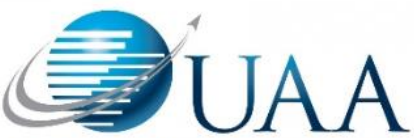

Collegiate Aviation Review

International

UNIVERSITY AVIATION

ASSOCIATION

\title{
Teaching Diversity, Equity, and Inclusion in Aviation Education
}

\author{
Jorge L. D. Albelo \\ Embry-Riddle Aeronautical University \\ Nicola O'Toole \\ Embry-Riddle Aeronautical University
}

\begin{abstract}
Over the last decade, many companies have begun to recognize the value of a diverse workforce, equity within the workforce, and inclusion practices. Recent global events have pushed the promotion of diversity, equity, and inclusion (DEI) in the aviation workplace and education higher on the priority list for many. Unfortunately, the aviation industry continues to have difficulty in attracting and retaining a diverse workforce. Notwithstanding this struggle in the industry, those in education must find ways to educate our students on topics relating to DEI. It is critically important that this training is rooted in research. The aviation industry is starting to see increased research initiatives to promote DEI among all generations. However, integrating DEI in the aviation classroom can be challenging, as many faculty members might not feel comfortable addressing the topic in relation to their courses. Therefore, this research focused on inclusive teaching and dynamic lecture strategies that will enable educators to reflect on critical consciousness, be mindful of implicit bias, and handle resistance while fostering a safe space.
\end{abstract}

\section{Recommended Citation:}

Albelo, J. L. D., \& O'Toole, N. (2021). Teaching diversity, equity, and inclusion in aviation education. Collegiate Aviation Review International, 39(2), 266-273. Retrieved from http://ojs.library.okstate.edu/osu/index.php/CARI/article/view/8400/7689 


\section{Practice Grounded in Research}

It is important to start this conversation with a consideration as to what defines diversity. Within a corporation or an educational institution, the definition typically falls in line with how that entity is measured. Equal Employment Opportunity, United States Bureau of Labor Statistics, and others measure corporations based on gender and ethnicity. However, people can be broken down into any number of groups based on factors such as socioeconomic status, social-psychological characteristics, and team interaction abilities, to name a few.

The airline industry has struggled to diversify its workforce based on gender and ethnicity measures. The most recent statistics published by the U.S. Bureau of Labor (2021) show that airline pilots are 94\% White, 3.4\% Black, 2.2\% Asian, 5\% Hispanic, and 5.6\% Female, and aircraft mechanics are $84.3 \%$ White, 10.8\% Black, 3.2\% Asian, 23\% Hispanic and $5.4 \%$ Female. Research shows us that striving for greater diversity is also good for business. A 2009 study found that companies with greater diversity had better sales, more customers, and larger market shares than those with less diversity (Herring, 2009). Additional research conducted in 2010 found that the more social psychological aspects of diversity play an equal or greater role in company success than the biodemographic measures of diversity (McMahon, 2010).

\section{Challenges of Teaching DEI}

Equally as important as maintaining a diverse workforce is an education program to support employees. A large meta-analysis of Diversity, Equity, and Inclusion training looked at the effectiveness of this type of training and the factors that impacted training effectiveness. Bezrukova et al. (2016) found several characteristics that made a positive impact in training. Training that was longer was more successful. Training that focused on diversity awareness and skills development resulted in more learning than training focusing on just awareness or just skills. The researchers also found that training that was supported by other programs within the company resulted in more positive outcomes. The training was also examined to determine factors that did not have a significant effect on training outcomes. The type of instructional mode and whether the training was mandatory or voluntary did not have a significant effect. Additionally, there was no difference between training that focused on one minority group (for example, women) versus training that took a more generalized approach. This meta-analysis serves as a general guide to some considerations when designing diversity, equity, and inclusion training. Unfortunately, not all training is well received. For example, a Washington Post article (Garvey, 1994) describes a diversity training seminar designed for FAA (Federal Aviation Administration) air traffic controllers in the early 1990s. The male controllers experienced a very "in-your-face" type of training that was intended to help them understand the problems of harassment in the workplace, in this case, specifically the harassment of women. The air traffic controller union stopped the training under an unfair labor practices complaint, and later one of 
the participants sued the Department of Transportation. This is just one example of training that had all the right intentions, but it was not executed appropriately. It is crucial to consider the audience and remember that many strong feelings are tied to the subject matter. That is not to say brush over the material, but be ready for challenging conversations and beware of an in-yourface type of approach.

\section{DEI in Aviation and Aviation Education}

Research on DEI training in the aviation industry is almost nonexistent. A research study in 2004 took two metrics that airlines are constantly looking at safety and customer service and found that the more training dollars were spent on diversity and other human resources, the better the company fared (Appelbaum, 2004). There is certainly a lot more work to be done in this area. Our role in the classroom is critical in preparing our students to head out into an industry that is striving for diversity, equity, and inclusion. There is a vast amount of research relating to this topic at all levels of education. (Wasserberg, 2014; Fischer, 2010). But, again, there is limited research on DEI and aviation education. The consensus is that making our classrooms more diverse, equitable and inclusive, has the potential to better educational outcomes and increase student retention. At an institution with aviation degree programs, the lack of enrollment diversity in the most basic measures gender, and race, are glaringly obvious. This leads to a classroom that may have only one female student or two students of color.

Furthermore, the lack of diversity in the aviation degree programs could also lead to students experiencing stereotype threats. Stereotype threat is defined as a fear of being judged based on belonging to a specific group or group-based stereotype (Spencer et al., 2016). For example, girls are bad at math. The effects of stereotype threat can lead to a reduction in working memory (Scmader \& Johns, 2003), impaired performance (Steele \& Aronson, 1995), and reduced sense of belonging (Good et al., 2012). This is just one example of why it is so important to consider our classroom environment and the opportunities to make it more inclusive.

While DEI practices in aviation education can pose a daunting challenge to overcome; however, Gannon (2020) suggested some ways professors might consider making their classroom more equitable and inclusive. Course design is one consideration: everything from the supporting materials, who is represented in those materials, what format they take to assignments, and how they allow students to demonstrate their knowledge. Gannon (2020) also emphasized identifying what biases professors may be taking into the classroom and finally creating a sense of belonging in the class. These are just a few of the many ways to strive for a better classroom environment for students of all backgrounds and experiences.

\section{Best Practices}

Inclusive teaching can be defined as a learning process that enables students to fulfill their learning needs in formal and informal educational environments (Figueroa, 2016). Furthermore, it allows teachers to feel comfortable in the open exchange of diversified thinking while enriching the learning environment, rather than just focusing on a particular problem (Figueroa, 2014). In a nutshell, inclusive teaching practices explore the importance of 
community and belonging as a foundation to student retention and success. Yet, because student needs change over the years, "being aware and sensitive to all learners and adjusting our teaching to factor each student's prior experience" (Figueroa, 2014, p. 49) ensures that teachers create a sense of belonging in the classroom.

Similarly, dynamic lecturing provides a framework that allows faculty to proactively optimize teaching and learning for all students. Dynamic lecturing principles enable the delivery of course content in multiple ways to reach all students. Primarily, faculty should make every effort to activate the students' prior knowledge as experiences influence what they perceive as important (Harrington \& Zakrajsek, 2017). Questioning for critical thinking is one strategy within dynamic lecturing that enables students the opportunity to retrieve previously stored information that can be applied in class (Harrington \& Zakrajsek, 2017). Therefore, to maximize the usefulness of dynamic lecturing, faculty should consider four simplified steps: 1) linking lessons to course goals, 2) exploring the lecture content, 3) exploring delivery methods, 4) timing sequence. Effective planning begins with a focus on goals. Faculty members should begin by documenting the course-level learning outcomes followed by a few goals for the lecture (Harrington \& Zakrajsek, 2017). Then, for each learning objective identified, the faculty member should make the best effort to help all students learn the content. This could range from connecting prior knowledge to new content, multimedia tools, or questions that lead to big picture ideas (Harrington \& Zakrajsek, 2017). Consequently, when exploring the different delivery methods options, faculty should keep a keen eye for the use of reflective exercises that bring attention to and emphasize the key learning objectives (Harrington \& Zakrajsek, 2017). Lastly, teachers should lay out the sequence in which the content will be presented to distribute the time appropriately to incorporate active learning opportunities.

\section{Benefits of Integrating DEI in Aviation Education}

Slee and Allan (2001) argued that while the benefits of integrating DEI practices in education are endless, the systematic implementation of DEI practices remains ambiguous. Though many factors play a role in the consistent implementation of inclusive practices, Hymel and Katz (2019) point out that there has to be a link between the feasibility of the academic curriculum and the ability for students to truly engage with one another and learn from their cross ingroup boundaries. Therefore, the first three steps towards integrating DEI practices in aviation education are using critical consciousness, recognizing implicit bias, and learning through handling resistance while fostering a safe space.

\section{Critical Consciousness}

Scholars have defined critical consciousness as "the ability to recognize systems of inequality and the commitment to take action against these systems" (El-Amin et al., 2017, p. 18). Some of the most noticeable results of practicing critical consciousness are higher academic achievement and higher professional aspirations. The Latino Pilot Association (LPA) is a clear example of critical consciousness in practice. The first collegiate chapter established by the LPA at Embry-Riddle Aeronautical University (ERAU) took the initiative of embracing critical consciousness. The Eagles chapter at ERAU formed and established the Empowering Latina Leader Aviators subcommittee (ELLAs) of LPA. ELLAs is comprised of a group of people who 
self-identify as either cisgender females, transgender females, or non-binary, committed to investing expertise and resources to support Latina pilots in the aviation industry. The ELLAs primary goals are to build confidence during flight training and spread awareness of mental health among pilots. It becomes evident that when people develop critical consciousness, they also develop resilience towards an industry that has created a barrier for them (El-Amin et al., 2017).

Furthermore, it is crucial for faculty to capitalize on teaching the language of inequity within critical consciousness. The concepts of the language of inequity refer to recognizing how racism is transmitted among people, which could be between individuals or by internalized racist beliefs (El-Amin et al., 2017). For example, it is known that in the aviation industry, women of color feel their gender first, followed by their race. These subtle microaggressions have been one of the main targets of ELLAs. By recognizing the language of inequity, individuals can develop resilience to face racism and break the oppressive social forces shaping our society.

\section{Implicit Bias}

Academic institutions should engage their female and male students equally, yet they should also recognize how gender-related issues affect implicit bias in the classroom. Educational research has shown that implicit bias can foster negative attitudes that lead to stereotypical behavior resulting from unconscious associations (Jackson et al., 2014; Staat, 2016). Staat (2016) further affirms that while implicit bias might not be a part of an individual's awareness, "[...] they can have a tremendous impact on decision making" (p. 30). Jackson et al. (2014) suggest that to reduce resistance to implicit bias teachings, the presenter should employ non-confrontational language to increase group cohesion as the dynamic takes place. A few strategies that faculty members can put forward are becoming mindful of their prejudice while increasing kindness and empathy towards others.

\section{Handling Resistance}

In any discussion involving DEI initiatives, there is a good chance that students will showcase resistant behavior. Research has confirmed that the teacher is the main reason students portrait resistant behavior (Baker \& Hill, 2017; Winckler \& Rybnikova, 2019). One of the most effective practices to reduce resistance in the classroom is to foster a safe space. Students who feel that their voices are heard without any sense of retribution tend to engage more in the class dynamic. Moreover, faculty members should be open to understanding the reasons for student resistance. Winckler \& Rybnikova (2019) point out that resistance from students is also a mechanism that enables them to reflect and change social conditions. Therefore, one could assume that when resistance is encountered in the classroom, the teacher has enabled the students to experience opposition as an expression of empowerment (Winckler \& Rybnikova, 2019) and has genuinely engaged in inclusive teaching practices.

Another strategy that faculty members could implement is ensuring that the learning objectives are free from personal worldviews. Faculty members who abstain from including their worldview as part of the lecture also ensure that their learning objectives are free from prejudice and unconscious bias. However, it would be ideal if the teacher could engage students 
in discussing their shared experiences. Nevertheless, the instructor should also require all experiences and opinions to be supported with evidence. Even difficult dialogues related to DEI in aviation education can be grounded in research. Ultimately, the discussion should lead towards shared understanding.

\section{Conclusion}

All in all, teaching and integrating DEI initiatives in aviation can be intellectually and emotionally challenging. Therefore, a good habit to develop is asking the students to reflect and suggest characteristics of practical discussion that they have engaged in previously. Even if the students ask for the teacher's experience, they should keep in mind not to generalize the experience of others. As challenging as the topics may be, the rewards benefit all involved. When students feel engaged, they are more successful and can experience a greater sense of belonging. Higher education institutions that promote DEI practices in aviation education are rewarded with greater retention of a diverse population. Businesses that employ students with DEI exposure gain employees with valuable skills beyond those required in a job description. Further research should explore the aviation students' perspectives of integrating DEI practices in their core courses. This research will enable leaders in the education field to refine their strategies and ensure that student and industry needs are met.

\section{Acknowledgments}

This research was partially supported by the Embry-Riddle Aeronautical University Faculty Research Development Program. Also, special thanks to the University Aviation Association (UAA) committee for accepting our proposal for an educational session and inviting us to publish this conference proceeding. 


\section{References}

Appelbaum, S. H., \& Fewster, B. M. (2004). Safety and customer service: Contemporary practices in diversity, organizational development and training and development in the global civil aviation industry. Management Research News, 27(10), 1-26. https://doi.org/10.1108/01409170410784301

Baker, E., \& Hill, S. (2017). Investigating student resistance and student perceptions of course quality and instructor performance in a flipped information systems classroom. Information Systems Education Journal, 15(6), 17-26

Bezrukova, K., Spell, C. S., Perry, J. L., \& Jehn, K. A. (2016). A meta-analytical integration of over 40 years of research on diversity training evaluation. Psychological Bulletin, 142(11), 1227-1274. https://doi.org/10.1037/bul0000067

El-Amin, A., Seider, S., Graves, D., Tamerat, J., Clark, S., Soutter, M., Johannsen, J., \& Malhotra, S. (2017). Critical consciousness: A key to student achievement. Phi Delta Kappan, 98(5), 18-23. https://doi.org/10.1177/0031721717690360

Figueroa, I. (2014). The value of connectedness in inclusive teaching. In Thomas, C. (2014). Inclusive teaching: Presence in the Classroom (pp. 45-49). Jossey-Bass.

Fischer, M. J. (2010). A longitudinal examination of the role of stereotype threat and racial climate on college outcomes for minorities at elite institutions. Social Psychology of Education, 13(1), 19-40. https://doi.org/10.1007/s11218-009-9105-3

Gannon, K. (2020, July 22). The case for inclusive teaching. The Chronicle of Higher Education. https://www.chronicle.com/article/the-case-for-inclusive-teaching

Garvey, M. (1994, September 9). Male FAA worker sues, alleging female 'gantlet' demeaned him. The Washington Post. https://www.washingtonpost.com/archive/politics/1994/09/09/male-faa-worker-suesalleging-female-gantlet-demeaned-him/69abd0be-ad30-4323-86ad-6f83a53ca167/

Good, C., Rattan, A., \& Dweck, C. S. (2012). Why do women opt out? Sense of belonging and women's representation in mathematics. Journal of Personality and Social Psychology, 102(4), 700-717. https://doi.org/10.1037/a0026659

Harrintong, C., \& Zakrajsek, T. (2017). Dynamic lecturing: Research-based strategies to enhance lecture effectiveness. Stylus.

Haymel, S., \& Katz, J. (2019). Designing classroom for diversity: Fostering social inclusion. Educational Psychologist, 54(4), 331-339. https://doi.org/10.1080/00461520.2019.1652098 
Herring, C. (2009). Does diversity pay? Race, gender, and the business case for diversity. American Sociological Review, 74(2), 208-224.

Jackson, S. M., Hillard, A. L., \& Schneider, T. R. (2014). Using implicit bias training to improve attitudes towards women in STEM. Social Psychology of Education, 17(3). 419-438.

McMahon, A. M. (2010). Does workplace diversity matter? A survey of empirical studies on diversity and firm performance, 2000-09. Journal of Diversity Management, 5(2), 37-48.

Schmader, T., \& Johns, M. (2003). Converging evidence that stereotype threat reduces working memory capacity. Journal of Personality and Social Psychology, 85(3), 440-452. https://doi.org/10.1037/0022-3514.85.3.440

Slee, R., \& Allan, J. (2001). Excluding the included: A recognition of inclusive education. International Studies in Sociology of Education, 11(2), 173-191. https://doi.org/10.1080/09620210100200073

Spencer, S. J., Logel, C., \& Davies, P. G. (2016). Stereotype threat. Annual Review of Psychology, 67(1), 415-437. https://doi.org/10.1146/annurev-psych-073115-103235

Staat, C. (2016). Understanding implicit bias: What educators should know. American Educator, 39(4). 29.

Steele, C. M., \& Aronson, J. (1995). Stereotype threat and the intellectual test performance of African Americans. Journal of Personality and Social Psychology, 69(5), 797-811. https://doi.org/10.1037/0022-3514.69.5.797

U.S. Bureau of Labor Statistics. (2021, January 22). 2020 annual averages - employed persons by detailed occupation, sex, race, and Hispanic or Latino ethnicity. U.S. Bureau of Labor Statistics. https://www.bls.gov/cps/cpsaat11.htm .

Wasserberg, M. J. (2014). Stereotype threat effects on African American children in an urban elementary school. The Journal of Experimental Education, 82(4), 502-517. https://doi.org/10.1080/00220973.2013.876224

Winckler, I., \& Rybnikova, I. (2019). Student resistance in the classroom: Functional instrumentalist, critical-emancipatory and critical-functional conceptualisations. Higher Education Quarterly. 